\title{
7. An assessment of the replacement of traditional irrigation systems by private wells in Tamil Nadu, India
}

\author{
Kei Kajisa \\ Aoyama Gakuin University, Japan and International Rice \\ Research Institute, the Philippines
}

In developing Asian countries, a major recent change in irrigation management is the rapid spread of private pumps and wells (modern irrigation systems). This process was accelerated by the introduction of the hydraulic drilling method in the 1980s and further by the development of the pump industry in China and India in the 1990s. The spread of modern systems is associated with the decline in traditional, communally managed irrigation systems.

An example of this trend can be found in Tamil Nadu, India. Traditional irrigation systems in this region are tank systems, which consist of a water storage area, sluices, and water supply channels. The water storage area is a small reservoir constructed across the slope of a valley to catch and store water. Water is controlled by the sluices, which are attached to the tank bank and is delivered to paddy fields through channels. This communal infrastructure has been collectively managed by informal local bodies. Although tank systems were the dominant source of irrigation until the early 1960s, in the last three decades a massive diffusion of private wells and pumps has occurred throughout India, including Tamil Nadu (Figure 1).

The dissemination of private wells provides more freedom for users to control irrigation water, in terms of the timing and amount of water delivered to their own fields, compared with collectively maintained tank systems and, thus, those who have access to wells can increase their yield and income (Palanisami 2000). This process has, however, been associated with the degradation of traditional tank systems as there are now less users to maintain them, which could negatively affect the agricultural production of remaining tank users. State statistics have aggregated these positive and negative effects of private wells, and show a net increase in the average yield of rice, a staple crop in the area, and an increase in the average income of farmers (Government of Tamil Nadu). 


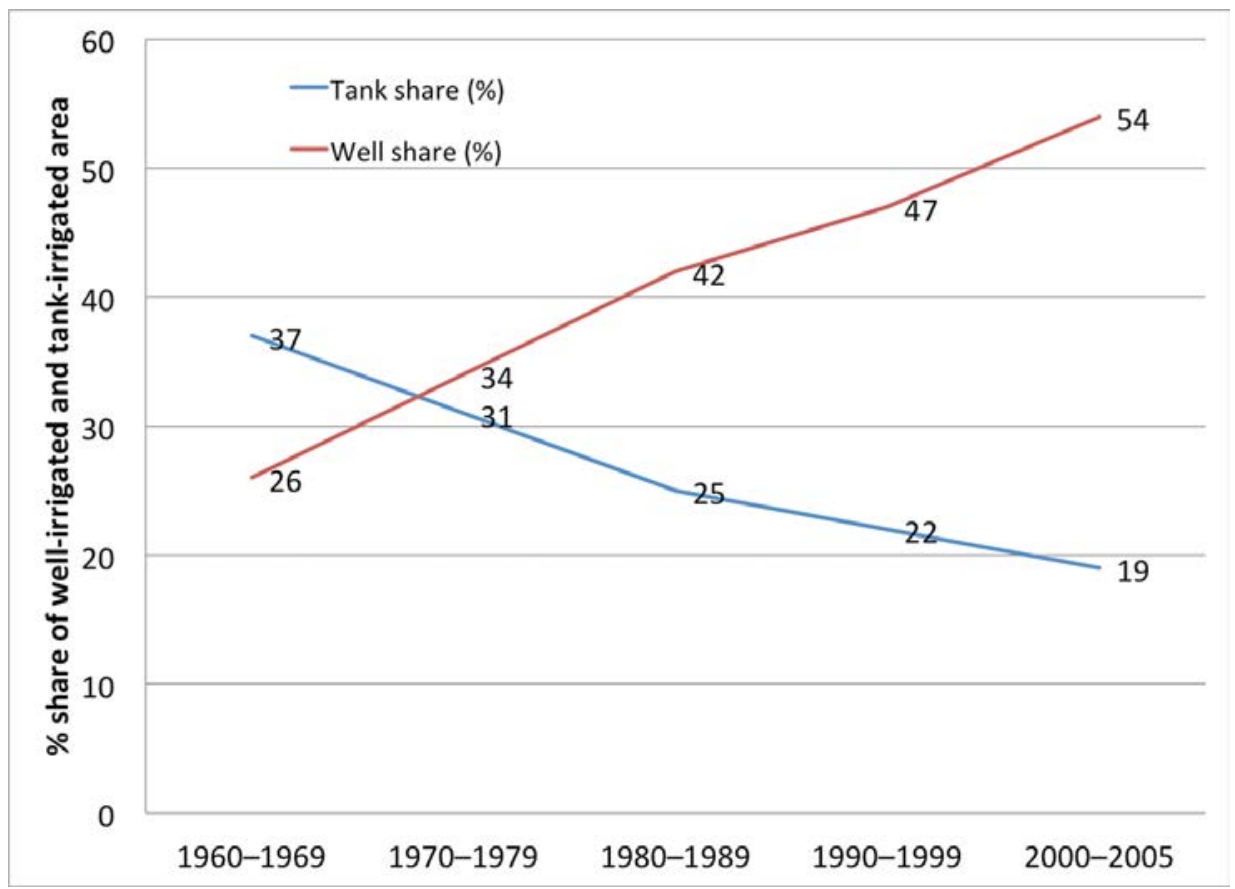

Figure 1: Percentage share of well-irrigated and tank-irrigated area in total irrigated area in Tamil Nadu from 1960 to 2005

Source: Author's research.

\section{Double tragedy among tank users and well} users

A closer look at the original data, however, suggests that the recent change to irrigation systems in Tamil Nadu is associated with increased poverty among a particular group of farmers: the tank users in high well-density areas. In principle, water from communal tanks is available to all farmers in the system command area. On the other hand, access to irrigation water from private wells is limited to owners and to those who can purchase water from the owners. Thus, with the decline in tank systems, farmers who are dependent solely on tanks will be disadvantaged, while farmers who have recourse to private wells can achieve higher levels of income and crop yield. Since this negative impact is large enough and the compensation of yield loss through income diversification is difficult, farmers without access to wells tend to fall into poverty. Table 1 summarises the rice yield, household income per capita, head count poverty ratio, and rice profit by irrigation status classified by the condition of tank 
(deteriorated or maintained) and by the access to wells (access or no-access). The worst situation across all indicators is that of farmers using deteriorated tanks without access to wells (column 1 of Table 1).

Table 1: Comparison of rice yield, income, poverty ratio, and rice profit by irrigation status

\begin{tabular}{|l|c|c|c|c|}
\hline Irrigation status & (1) & (2) & (3) & (4) \\
\hline Condition of tank & Deteriorated & Maintained & Deteriorated & Maintained \\
\hline Access to wells & No-access & No-access & Access & Access \\
\hline Rice yield (t/ha) & 3.2 & 3.6 & 4.4 & 4.1 \\
\hline $\begin{array}{l}\text { Household Income per } \\
\text { capita (Rs./month) }\end{array}$ & 262 & 309 & 561 & 589 \\
\hline $\begin{array}{l}\text { Head count poverty } \\
\text { ratio }{ }^{b}\end{array}$ & 0.67 & 0.59 & 0.30 & 0.24 \\
\hline Rice profit (Rs./ha) & -929 & 4,801 & 1,897 & 5,619 \\
\hline
\end{tabular}

Source: Author's research. (a) The value is converted into a per capita base using the adult equivalent of household members. (b) The international poverty line of US\$1 per day, adjusted for purchasing power parity, has been used. Use of the national poverty line of Rs. 324 (equivalent to US\$36.40 at PPP exchange rate) monthly per capita for 1993-94 does not change the qualitative results.

The story does not end here. Since groundwater is a typical example of a common resource, under open access private users do not take into account the existence of a negative externality that their use imposes on other users. Hence, the likely outcome is the overexploitation of groundwater beyond a socially optimal level and, in the medium- to long-term, more costly irrigation as wells have to pump from deeper below the surface. Eventually, well users become unable to earn as much profit on rice as they did previously due to the higher electricity and infrastructure costs of pumping water from a depleted aquifer. Table 1 shows that among the well users (columns 3 and 4), the profit with the deteriorated tank is much lower than the other case, provided that the deterioration occurs in the high well-density areas (Kajisa et al. 2007). A detailed regression analysis supports this story, which can be found in the original piece of research assessing the introduction of the new irrigation systems in Tamil Nadu that this paper has summarised (Kajisa 2012). In this way, the replacement of tanks by private wells results in a double tragedy: increased poverty among non-users of wells and potentially no long-term profit among well users.

\section{Toward a win-win solution}

We call the above-mentioned story a tragedy because no individual currently has an incentive to change their actions. With regard to the first tragedy, the 
negative effect on the farmers with no access to wells has been created by the decline in collective management of tanks. Since well users do not suffer as much as non-users from this decline, they have little incentive to correct it. The second tragedy, related to the groundwater table, is a typical example of the 'tragedy of the commons'. Since the root of the problem is a negative externality transferred by each individual well user onto other well users, no incentive for correction exists. Without policy interventions, the correction of this double tragedy is difficult.

My simulation has shown that the revitalisation of collective tank management could effectively reduce poverty. In addition, revitalisation could supplement groundwater aquifers through percolation and thus alleviate the problem of overexploitation. Reducing the number of electric pumps could also be effective to avoid overexploitation. The first option for this purpose should be the abolition of the policy of free electricity for agricultural use, which may be politically difficult. Another strategy could be to charge a progressive sales tax on higher horsepower pump sets and deeper drilling of bore wells in order to deter over-dissemination and over-deepening of well irrigation systems. The government could then use the revenues from electricity, or from a tax, for tank revitalisation projects. This transfer could be considered legitimate because well users would receive an indirect benefit from the revitalised tanks, in that water from them permeates to re-supply groundwater aquifers.

Dr Kei Kajisa is a Professor at Aoyama Gakuin University in Japan and an Adjunct Scientist at the International Rice Research Institute (IRRI) in the Philippines. His research interest includes institutional design for sustainable collective irrigation management in Asia. The article is based on an original piece of research published in Water Policy, vol. 14: 'The double tragedy of irrigation systems in Tamil Nadu, India: assessment of the replacement of traditional systems by private wells'.

\section{References}

Government of Tamil Nadu (various issues). 'Season and crop report', Department of Economics and Statistics, Government of Tamil Nadu, Chennai.

Kajisa K., 2012. 'The double tragedy of irrigation systems in Tamil Nadu, India: assessment of the replacement of traditional systems by private wells', Water Policy 14:371-90.

—, Palanisami, K. and Sakurai, T., 2007. 'Effects on poverty and equity of the decline in collective tank irrigation management in Tamil Nadu, India', Agricultural Economics 36:347-62.

Palanisami, K., 2000. Tank irrigation: revival for prosperity. Asian Publishing Service, New Delhi. 
This text taken from Global Water: Issues and Insights by R. Quentin Grafton, Paul Wyrwoll, Chris White and David Allendes, published May 2014 by ANU Press, The Australian National University, Canberra, Australia. 